\title{
"É o que está acontecendo": proposição didática para o desenvolvimento do letramento em língua estrangeira a partir do gênero tweet
}

\author{
"Es lo que está ocurriendo": proposición didáctica para el \\ desarrollo del letramento en lengua extranjera a partir del \\ género tweet
}

\begin{abstract}
"It's what's happening": a didactic proposal for the literacy development in foreign language to wards the tweet genre
\end{abstract}

\author{
Aldimeres Ferraz da Silva* \\ Ticiane Rafaela de Andrade Moreno**
}

\begin{abstract}
RESUMO: Desenvolvemos esta proposta didática para o ensino de línguas estrangeiras, destinada ao Ensino Médio, visando formar alunos autores críticos e reflexivos na cibercultura. Para tanto, utilizamos como cunho teórico-metodológico a Pedagogia dos Multiletramentos (GRUPO DE NOVA LONDRES, 2000; ROJO, 2012), buscando desenvolver o letramento digital, crítico, colaborativo e multissemiótico, a partir do processo de escrita colaborativa (ALLEN et al, 1997; MARCHIORI, GREEF, 2014; LOWRY, CURTIS, LORWY, 2004) e do estudo do gênero textual tweet (SILVA, 2013). De modo geral, desejamos que este trabalho possa contribuir com o ensinoaprendizagem de língua estrangeira na educação pública brasileira e, sobretudo, se constitua como caminho didático-metodológico a ser percorrido e lapidado no dia a dia das salas de aula, em prol da formação de alunos críticos e humanamente envolvidos na sociedade tecnológica contemporânea.
\end{abstract}

PALAVRAS-CHAVE: Ensino de línguas estrangeiras. Letramento digital. Escrita colaborativa. Gênero tweet.

\footnotetext{
*Licenciada em Letras com habilitação dupla em língua portuguesa e em língua espanhola pela Universidade Estadual do Norte do Paraná, campus Jacarezinho-PR. Especialista em Estudos Linguísticos e Literários pela Universidade Estadual do Norte do Paraná. Mestranda no Programa de Pós-Graduação em Estudos da Linguagem pela Universidade Estadual de Londrina. Professora de Língua Portuguesa e Língua Espanhola - Secretaria Estadual de Educação do Paraná. aldimeresf@gmail.com

**Licenciada em Letras com habilitação dupla em língua portuguesa e em língua inglesa pela Universidade Estadual do Norte do Paraná e em Pedagogia pela Universidade Metropolitana de Santos. Especialista no Ensino de Línguas Estrangeiras pela Universidade Estadual de Londrina. Mestranda no Programa de Pós-Graduação em Estudos da Linguagem pela Universidade Estadual de Londrina. Professora de Língua Inglesa - Secretaria Estadual de Educação do Paraná. ticiane91@bol.com.br
} 
RESUMEN: Desarrollamos esta propuesta didáctica para la enseñanza de lenguas extranjeras destinada a la Enseñanza Media, con el objetivo de formar alumnos autores, críticos y reflexivos en la cibercultura. Para esto, utilizamos como fundamentación teórico-metodológica la Pedagogía de los Multiletramentos (GRUPO DE NOVA LONDRES, 2000, ROJO, 2012), buscando desarrollar el letramento digital, crítico, colaborativo y multisemiótico, a partir del proceso de escritura colaborativa (ALLEN et al, 1997; MARCHIORI, GREEF, 2014; LOWRY, CURTIS, LORWY, 2004), y del estudio del género textual Tweet (SILVA, 2013). En general, deseamos que este trabajo pueda contribuir con la enseñanza-aprendizaje de lengua extranjera en la educación pública brasileña y, sobre todo, se constituya como camino didácticometodológico a ser recorrido y lapidado en el día a día de las aulas, en favor de la formación de alumnos críticos y humanamente envueltos a la sociedad tecnológica contemporánea.

PALABRAS CLAVE: Enseñanza de lenguas extranjeras. Letramento digital. Escritura colaborativa. Género tweet.

ABSTRACT: We developed this didactical proposal for the foreign language teaching for High School graders, aiming to develop the students' authorship, criticality and reflexivity in the cyberculture. Therefore, our theoretical and methodological foundations are grounded in the Multiliteracies Pedagogy (NEW LONDON GROUP, 2000; ROJO, 2012) that works on the digital, critical, collaborative and multissemiotic literacy; in the process of collaborative writing (ALLEN et al, 1997; MARCHIORI, GREEF, 2014; LOWRY, CURTIS, LORWY, 2004); and in the study of the text genre tweet (SILVA, 2013). In general, we have the intention of achieve our work to contribute to the foreign language teaching and learning in the Brazilian public education and, above all, to become a didactical and methodological way to be walked and improved in the everyday foreign language classes, in favour of the education of the students critically and humanely in the contemporary technological society.

KEY WORDS: Foreign languages teaching. Digital literacy. Collaborative writing. Genre tweet.

\section{Considerações iniciais}

De acordo com Lowry, Curtis e Lowry (2004), a demanda do mundo globalizado é a colaboração entre membros de um determinado grupo, intensificada pelo uso da internet. No entanto, os nossos alunos da escola pública ficam muito à margem dessas práticas de letramento digital, visto que a escola não está equipada com tecnologia que nos subsidie, não tem a assistência técnica necessária e há uma lacuna na formação inicial e continuada dos professores nesse sentido. Marchiori e Greef (2014) apontam, por exemplo, a falta de subsídios que os professores da escola pública têm para avaliar e 
mensurar graus de contribuição, colaboração e engajamento, bem como de estabelecer critérios para uma avaliação de processo da aprendizagem. Isso sem mencionar o baixo grau de letramento digital de parte dos professores.

Nós, portanto, alunas de um programa de pós-graduação de linguagem e professoras da rede estadual do Paraná, gostaríamos de oferecer aos professores não só possibilidades para práticas didáticas ligadas ao uso de ferramentas digitais, mas também que agreguem o ato complexo de ler e de escrever em língua estrangeira e o uso da língua estrangeira em contextos reais com fins emancipatórios. Para isso, a nossa proposição faz uso da rede social twitter e visa à produção textual do gênero tweet, a partir de leituras resistentes e críticas de representações sobre o cotidiano em redes sociais. Pretendemos fazer o aluno refletir a forma como as construções utilizadas pelos usuários do twitter com grande popularidade refletem imaginários sociais e qual o papel do cidadão ativo perante a eles. A proposta não foi construída em uma língua estrangeira específica para que o professor possa fazer as possíveis adequações dentro da língua que leciona.

O objetivo geral desta proposição didática é desenvolver a capacidade autoral dos alunos de forma colaborativa e reflexiva referente à produção escrita ao falar sobre a própria experiência de vida em língua estrangeira. Diante disso, os objetivos específicos são: 1) fomentar a competência escritora em língua estrangeira em contexto real de uso e em processo colaborativo como instrumento transformador da realidade; 2) aprofundar a competência leitora crítica e reflexiva em língua estrangeira sobre os usos das redes sociais; 3) compreender e utilizar o gênero tweet em suas características verbais e multimodais; 4) refletir sobre a cultura da remixagem presente em redes sociais interativas; 5) avaliar e analisar processos de tweets textuais e imagéticos próprios e alheios.

Queremos ressaltar o caráter flexível e adaptável da nossa proposição didática, servindo apenas como um arcabouço de ideias para o professor, lembrando da importância da construção da proposta didática professor-aluno, na qual os alunos participam ativamente nas decisões didático-pedagógicos dos 
processos de ensino e aprendizagem. Para os processos pedagógicos que pretendemos sugerir, entendemos que há alguns conjuntos teóricos que precisam ser (re)visitados para fundamentar a nossa proposta. Embora não utilizemos uma ferramenta digital de escrita colaborativa, pretendemos que uma escrita colaborativa ocorra a partir do trabalho dos alunos na postagem de seus tweets. A proposta também empreende recriação em ambientes digitais, por isso apropriamo-nos da ciber-cultura-remix (LEMOS, 2015) dos letramentos multissemióticos e multimodais. Como suporte metodológico, delinearemo-nos fundamentadas na Pedagogia dos Multiletramentos do New London Group.

\section{Ciber-cultura-remix}

Para Lemos (2005), a ciber-cultura-remix é "conjunto de práticas sociais e comunicacionais de combinações, colagens, cut-up de informação a partir das tecnologias digitais" (LEMOS, 2005, p. 1). Hoje vivemos a época da "cibercultura-remix", em que o princípio da "remixagem" contribui para a nova configuração social, na qual o uso das Tecnologias Digitais de Informação e Comunicação (TDIC) "alteram os processos de comunicação, de produção, de criação e de circulação de bens e serviços" (LEMOS, 2015, p. 1). Através da grande interatividade social e da liberação da emissão, hoje podemos ser produtores e emissores de informações em tempo real, o que possibilita ações importantes como a escrita colaborativa em ambientes digitais, que inclusive contribui para tornar cada vez mais próximas as noções de leitor e produtor de texto.

Nesta perspectiva, a internet tem se configurado como principal responsável pela produção e emissão de inúmeros conteúdos em ambiente digital, por meio de ferramentas diversificadas como o e-mail, os chats, os blogs, os sites institucionais, os podcasts e as redes sociais. Nesse sentido, "tudo está em rede" e a utilização de dispositivos móveis torna ainda mais prático o acesso a infinidade de dados que é compartilhada o tempo todo na $w e b$, já que "de qualquer lugar do mundo, qualquer indivíduo pode, teórica e 
tecnicamente, ter acesso aos mais variados tipos de informações e recombinálas, usando-as como bem entender" (NERY, 2015, p. 03).

Outra questão importante, e que se tornou crítica em tempos de "cibercultura-remix", é o copyright, os direitos autorais. Em uma cultura de remixagens, em que prevalece a coletividade e a produção, a emissão e a recepção rápida de dados, repleta de "fusão de ideias e autores, de criação inacabada, recombinante" (NERY, 2015, p. 3), não cabe mais pensar em direitos autorais, já que tudo é coletivo, re-mixado e reconfigurado. Assim, conforme aponta Nery (2015), passa-se a pensar em CreativeCommons ${ }^{1}$, em obras criativas disponíveis através de uma licença para utilização livre e aberta para cópias, recombinações e compartilhamentos.

Assim, a 'ciber-cultura-remix' vai abrindo margem para a disseminação da arte eletrônica, por meio da qual todos têm a oportunidade de produzir e emitir suas criações artísticas em CreativeCommons. Conforme Lemos (2015), essa criação artística na cibercultura, "coloca em sinergia processos interativos, abertos, coletivos e planetários, problematizando as noções de espaço e de tempo, o lugar do espectador e do autor, os limites do corpo e do humano, as noções de real e de virtual" (LEMOS, 2015, p. 4). Logo, observamos que a internet tem aberto inúmeras possibilidades para os trabalhos artísticos, potencializando as ações já realizadas como, por exemplo, as "músicas eletrônicas, a 'bodyarte', a 'web-arte', a 'net-arte', os hipertextos, a robótica, a realidade virtual, as instalações interativas" (LEMOS, 2015, p. 04), além de outras formas relacionadas à literatura, ao cinema, ao teatro e à dança.

\footnotetext{
${ }^{1}$ Conforme Branco e Britto (2013), CreativeCommons é um projeto criado por uma organização não governamental sem fins lucrativos, fundada no ano de 2001, com sede em São Francisco, na Califórnia. O objetivo é a promoção do acesso universal à pesquisa, à educação e à participação cultural, perseguindo o ideal de um mundo de conhecimento livre, facilmente difundido e modificado. "É essa ideia que atrai colaboradores, desde grandes grupos empresariais até indivíduos isoladamente, que se utilizam das ferramentas oferecidas e vislumbram uma nova forma de encarar a produção autoral na internet. São eles que sustentam o CreativeCommons com suas doações" (BRANCO, BRITTO, 2013, p. 66).
} 


\section{Escrita colaborativa}

O fenômeno social da escrita colaborativa não é algo novo, ela acontece em nossa sociedade desde os primórdios da própria escrita. No entanto, nas aulas de Produção Textual na escola, em sua maioria, a produção é vista como um ato individualizado e artificial em que o aluno se defronta com um tema, um papel e uma caneta ou lápis. Isso contrasta muito com a realidade em que a grande maioria dos jovens está inserido, a world wide web, em que se dissolvem as noções estáticas de tempo, espaço e de autoria.

Soares (2002) aponta a permanente mutabilidade do hipertexto e suas possibilidades interativas que questionam a noção de pertencimento de um texto a um determinado autor, concebendo a autoria dos hipertextos como uma multiautoria. A possibilidade da escrita digital torna muito mais visível o que 0 círculo de Bakhtin (2003) concebe como dialogismo, o diálogo entre o eu e o outro em que se perde a noção dessas fronteiras previamente definidas; polifonia, as vozes conflitantes do diálogo; plurivocalidade, as diferentes posições sociais e identitárias que quando colidem em um discurso tornam-se heteroglossia. As vozes sociais tornam-se mais, por um lado, evidentes no tecido da comunicação digital e, por outro, veladas e persuasivas, o que faz necessário que a escolarização promova a inserção crítica do aluno nessas práticas sociais.

$\mathrm{Na}$ literatura, as definições de escrita colaborativa tocam alguns pontos principais, como a produção de um documento compartilhado, divisão de poder de decisão e responsabilidade (ALLEN et al, 1997; MARCHIORI, GREEF, 2014), negociação de significados, repartição de trabalho, organização das contribuições individuais, discussões sobre autoridade entre o grupo (LOWRY, CURTIS, LORWY, 2004), inexistência de hierarquia, liderança partilhada (MARCHIORI, GREEF, 2014), consenso (MARCHIORI, GREEF, 2014; LOWRY, CURTIS, LOWRY, 2004) e interação substancial entre os participantes na produção no documento (ALLEN et al., 1997). 
Sevilla-Pavón (2015) aponta que a colaboração tem sido uma grande mola propulsora na criação de softwares e movimentos artísticos livres. A autora ainda assevera que a escrita colaborativa deve ser uma prática recorrente principalmente no ensino de língua estrangeira em que os diálogos entre os diferentes letramentos plurilíngues se comunicam, além de que, por meio da tecnologia, a audiência social mais próxima do contexto de uso de uma língua estrangeira é mais fácil de ser alcançada. A escrita colaborativa na tecnologia, além de imbricar diversas vozes sociais e diversas línguas e variantes, também reúne diversas linguagens multimodais que podem ser constantemente atravessadas autoralmente por diversos discursos.

Hoje, em uma época povoada de hipertextos em que o pensamento é muito mais mobile permeado pelos contatos por meio das redes sociais, as opiniões e vozes colidem, muitas vezes, não de forma colaborativa, mas em forma de discursos simbólicos de violência, criando-se verdadeiras redes de ódio. Atividades colaborativas que promovem o exercício democrático das vozes dos alunos e de suas vozes sociais podem permitir que os alunos desenvolvam diversas capacidades sociais para o exercício da cidadania. Estão embasadas em noções de complementaridade, compartilhamento, compreensão, negociação (PINHEIRO, 2011; FUNG, 2010), metacognição (BUSH, ZUIDEMA, 2013), resolução de problemas e por meio delas os alunos se tornam aprendizes e professores, à medida que interagem com os diferentes com os complexos mentais e atuam na formação de conceitos de seus colegas (VYGOTSKY, 1998). Marchiori e Greef (2014) consideram que propostas de escrita colaborativa são construtivistas sociais, pois se fundamentam em construção de conhecimento e artefatos sociais. A aprendizagem, nesse sentido, é sócio-histórica, pois considera os aspectos sócio-históricos de uso da linguagem e a aprendizagem em uma direção sociointeracional, utilizando a Zona de Desenvolvimento Proximal (VYGOTSKY, 1998) como um espaço a ser explorado.

Allen et al. (1987) chamam atenção para a distinção entre trabalho de grupo e colaboração, que podem ser coisas bem distintas, se as interações 
produzidas não forem qualitativas. Essencial também é o envolvimento do professor nesse processo como aprendente, buscando o compartilhamento do poder de decisão com a classe e a resolução de problemas junto de seus alunos. Ao professor cabe um acompanhamento constante das interações realizadas entre os discentes (FUNG, 2010), observar e intervir se há espaço para todos produzirem, engajamento de todos os membros do grupo (BUSH, ZUIDEMA, 2013) e retroalimentação dos processos de criação, além do conhecimento das ferramentas digitais (MARCHIORI, GREEF, 2014). O engajamento é uma decorrência da discussão e negociação com os alunos sobre o projeto de classe e a clareza dos objetivos do projeto, para que se torne significativo para eles.

\section{Multimodalidade e pedagogia dos multiletramentos}

Prediger e Kersch (2013) elaboram algumas reflexões interessantes sobre o caráter multimodal da linguagem e suas práticas de ensino. Conforme as autoras, considerando que estamos inseridos em uma conjuntura sóciocibercultural, que cada vez mais exige práticas plurais de letramento, sobretudo de letramento digital, cabe-nos refletir sobre as múltiplas linguagens que compõem os textos que circulam em nossa sociedade. Sobre isso, Rojo (2012) explica que nestes textos são agregados novos elementos e novas formas de organização e exposição, que proporcionam uma interação entre múltiplas linguagens.

Para Coscarelli (2012, p. 142), com a chegada dessa nova forma de escrever torna-se necessário "repensar o sentido da palavra 'texto', não como um novo conceito, mas como uma ampliação desse conceito para outras instâncias comunicativas, [...] é preciso entrar na semiótica e aceitar a música, o movimento e a imagem como parte dele". Assim, Vieira e Silvestre (2015) afirmam que a composição desse tipo de texto é bastante rica, já que engloba imagens, cores, movimentos, sons e palavras escritas. 
Pensamos que a produção de textos multimodais exige que o produtor tenha um amplo domínio e conhecimento sobre as diversas linguagens que compõem sua criação, e sobre os modos como elas podem ser organizadas e linkadas. Desse modo, considerando que a liberação da emissão de dados é uma forte característica da cibercultura, entendemos que todos, inclusive nossos alunos, podem ser produtores e leitores desses textos em ambientes digitais, desenvolvendo práticas devidamente situadas de múltiplos letramentos, que contemplem os seguintes aspectos: a multilinearidade (de constituição, apresentação e recepção do texto); a hipermodalidade (que une multissemiosee multimodalidade) e a interatividade (entre as diferentes linguagens; entre o sujeito e a máquina; e entre os diferentes sujeitos) (PINHEIRO, 2013).

Nesta perspectiva, torna-se relevante a realização de um trabalho cuidadoso e profícuo quanto ao ensino e aprendizagem destes textos na escola pois, como afirmam Vieira e Silvestre (2015), normalmente os alunos sabem utilizar e juntar os textos de várias linguagens distintas, mas "poucos aprenderam a traçar conexões entre esses textos, a distribuí-los numa sequência pertinente, a dar um tratamento especial ao texto escrito, a expor os elementos de forma coerente no espaço da tela, a produzir elementos em saliência" (VIEIRA; SILVESTRE, 2015, p. 214). Desse modo, pensamos que é importante que a escola utilize seus espaços de aula também para ensinar aos alunos sobre como aproveitar as inúmeras possibilidades que a linguagem multimodal e a cibercultura oferecem, a fim de que saibam produzir textos animados, sonoros, visuais etc., aprimorando o domínio das habilidades técnicas de uso do computador e de outras mídias.

Segundo Rojo (2012), o termo multiletramento não indica somente letramentos múltiplos/plurais, mas sim a multiplicidade social e semiótica de constituição dos textos utilizados pelas pessoas. Hoje, convivemos com uma grande variedade de textos híbridos, que demandam inúmeros letramentos. $\mathrm{E}$ ao pensarmos nesta variedade cultural, abarcamos todas as práticas situadas experienciadas por nossos alunos, notadamente as práticas que a escola por 
muito tempo deixou de valorizar, como a arte e a música produzida e apreciada por esses próprios alunos que sonham em ser, por exemplo, rappers, funkeiros, pagodeiros, sertanejos, youtubers, já que "a produção cultural atual se caracteriza por um processo de desterritorialização, de descoleção e de hibridação que permite que cada pessoa possa fazer sua própria coleção, sobretudo a partir das novas tecnologias" (ROJO, 2012, p. 16).

$E$, conforme a autora, essas novas produções exigem uma nova ética e uma nova estética, de modo a pensar justamente em CreativeCommons, em produção colaborativa, deslocada das regras de direitos autorais; além de desenvolver práticas sociais com análise crítica, reflexão e desvelamento do senso comum. Um trabalho efetivo com produções discursivas, em eventos de letramentos que conduzam a questionamentos e resistência às relações sociais de poder e de exclusão, que afetam a dignidade humana e seus valores (AGUIAR; FISCHER, 2012).Neste sentido, professor e alunos se constituem como designers, remixers, produtores e transformadores socialmente ativos, considerando que os "objetivos social e político dos multiletramentos são situar os professores e os estudantes como participantes ativos na mudança social, os designers ativos do futuro social" (JEWITT, 2008, p. 245).

Por isso, o Grupo de Nova Londres pensou essa pedagogia para ser desenvolvida através de 'Prática Situada', de 'Instrução Aberta', de 'Posicionamento Crítico' e de 'Prática Transformada'. Assim, é possível que os alunos se tornem cidadãos críticos, que agem também por meio de processos digitais (XAVIER, 2007). Nesse sentido, organizamos no seguinte quadro os passos elementares da Pedagogia dos Multiletramentos:

Quadro 1: Componentes que integram o "Como" da Pedagogia dos Multiletramentos

Prática Situada: imersão na experiência e utilização de designs de significado disponíveis, incluindo aqueles relacionados à experiência de vida dos alunos e simulações dos relacionamentos a serem encontrados em espaços profissionais e públicos.

Instrução Aberta: compreensão sistemática, analítica e consciente dos designs de significados e dos processos de Design, o que requer a introdução de metalinguagem explícita, que permite descrever e interpretar elementos de Design de diferentes modalidades de 
significados.

Posicionamento Crítico: interpretação do contexto social e cultural de desenhos particulares de significados, o que envolve o distanciamento dos alunos do objeto de estudo/discussão para o visionamento crítico em relação ao contexto.

Prática Transformada: transferência no processo de construção de significados, o que permite que os significados transformados (o Redesenhado) sejam trabalhados em outros contextos e espaços culturais.

Fonte: Elaborado pelas autoras, com base em GRUPO DE NOVA LONDRES (2000).

\section{O gênero textual/discursivo tweet: algumas elucidações teóricas}

O gênero textual/discursivo tweet é produzido dentro da rede social twitter que foi fundada em 2006. Essa rede social é utilizada para a prática de microblogging em um número limitado de caracteres e permite que os usuários tenham acesso às produções de uns dos outros e interajam dessa forma ${ }^{2}$. 0 funcionamento dessa rede social não é o mesmo desde que foi criada, pois essa foi se adaptando à forma com que os usuários a conduziam. Hoje ela estruturase em um paradigma de seguir pessoas, informações, grupos, marcas etc.; compartilhar hipertextos; buscar em tempo real; agrupar por temas (GREENHOW, GLEASON, 2012). Os usuários do twitter criam um perfil em que dispõem de interesses, questões profissionais e pessoais e seus históricos de tweets. O gênero tweet é um hipertexto, pois, pela sua audiência, na maioria dos casos, ser pública, o conteúdo pode ser vinculado a diversos links da web: vídeos, imagens, reportagens, gifs, notícias, entre outros.

Alguns mecanismos do twitter promovem interatividade, como: o uso de @ mais o nome de um usuário significa que você está dialogando com ele, as letras RT que querem dizer que você está retuitando um tweet já publicado (compartilhando o tweet de outra pessoa na sua conta sem alterá-lo), a mensagem direta (DirectMessage - DM) é uma ferramenta de comunicação que permite ao usuário enviar um tweet privado ao outro, a hashtag (\#) em que os

2É possível acessar o twitter pelo site: <https://twitter.com/?lang=pt-br>. Para produzir tweets e interagir com outros usuários, é necessário criar uma conta. 
usuários utilizam palavras e frases para vincular o seu tweet a um tema mais abrangente que pode estar relacionado a outros tweets com a mesma hashtag, a qual pode ser um tema, problema, questão, estado de espírito, sentimentos (SILVA, 2013). O twitter modificou e ressignificou o blog, a principal alteração foi na organização composicional em virtude do número de caracteres limitar-se a 140, pois precisa permitir o envio de mensagens via SMS e passou a ser chamado de microblog (GREENHOW, GLEASON, 2012). O compartilhamento de informações intensifica-se no twitter, pelo fato de ter uma audiência pública e se constituir uma rede social (SILVA, 2013).

Autores como Silva (2013) defendem a rede social twitter como um gênero textual e, se assim o for, ele é um gênero guarda-chuva que abriga vários outros gêneros, em virtude do seu caráter hipertextual, mas sob outras perspectivas ele pode ser considerado um suporte (MARCUSCHI, 2003). Sobre as diferentes categorias que podemos abordar o conteúdo dos tweets, Zago (2008) aponta: 1) a dimensão pessoal, o que Silva (2013, p. 68) chama de "mensagens de conteúdo irrelevante, muitas vezes com o uso da função fática da linguagem"; 2) a dimensão de trocas e conversações; 3) a dimensão de compartilhamento de informações, inclusive de profissionais de áreas que são responsáveis pela divulgação de informações como de outros grupos; 4) a apropriação dos tweets como ação social, em que temos observado mais recentemente as redes sociais como catalisadoras das mobilizações sociais, fomentadoras de mudanças políticas, formadoras do pensamento ideológico e instrumento de protesto e crítica. Silva (2013) aponta o retweet como uma forma importante nesse embate em que se valoriza ou desvaloriza-se o discurso do outro, por meio de uma pluralidade de vozes. E, por fim, o que ele chama de metapostagem, que cremos serem tweets que têm como conteúdo temático a própria natureza do twitter.

Quanto à linguagem do tweet, os limites entre oralidade e escrita diluem-se, já que a escrita digital comunica-se com os gêneros orais (MARCUSCHI, 2001; SILVA, 2013). Isso, ao contrário da crença comum, não diminui a complexidade da tarefa de escrever, "a limitação do texto a 140 
caracteres exige daquele que escreve um domínio de síntese, coesão textual, vocabulário e até uma dose de criatividade" (SILVA, 2013, p. 70). Marcuschi (2001), ao falar sobre a natureza do hipertexto, observa que a sua organização é flexível, é uma produção situada, porém as linhas entre destinatário e produtor confundem-se, pois, apesar de haver uma identidade central, a interatividade a dilui.

Dentro dessa gramática do hipertexto, a multimodalidade ocupa um espaço vital. A multimodalidade no gênero tweet extrapola a prática de copiar e colar hyperlinks ou inserir imagens, vídeos e outros hipertextos, configurandose como uma extensa prática de reconstrução em que as palavras nossas e do outro indistinguem-se num exercício de ler, criar, escrever, transformar, inclusive combinando diferentes recursos semióticos em um processo de remixagem (GREENHOW, GLEASON, 2012).

O movimento dos usuários modelarem a rede social não é unilateral, pois as pesquisas já apontam a mudança no comportamento social em relação ao uso das redes sociais, especialmente para adolescentes e jovens que encontram novas formas de se introduzirem socialmente e se relacionar (GREENHOW e GLEASON, 2012). Davies (2002 apud GREENHOW e GLEASON, 2012), ao investigar os usos que adolescentes fazem da rede social Facebook, indica que as fotos postadas delineiam a sua história imagética a partir delas e dos comentários e reações que provêm das interações. Na mesma direção, Silva (2013) comenta que não é a conexão dos outros com os fatos da sua vida que faz a diferença e sim que a sua história possua um lócus no espaço virtual. Santana (2014) denomina essa necessidade de visibilidade como um capital social forjado, o que modifica a forma como os indivíduos experienciam e compreendem a própria vida.

O uso de redes sociais também modifica as relações mentais realizadas pelos indivíduos e são compreendidas como novas práticas de letramentos (GREENHOW e GLEASON, 2002; ROJO, 2012; SOARES, 2002). Essas práticas de letramento estão relacionadas com a criação de textos multissemióticos, 0 engajamento discursivo em novas formas de comunicação, compartilhamento e 
negociação de significados, cruzando as fronteiras nacionais e de línguas (GREENHOW e GLEASON, 2012). Silva (2013) implica que esses novos processos têm alimentado a ideia de uma consciência coletiva que nasce do compartilhamento de vozes e discursos, no sentido bakhtiniano.

Refletir sobre isso se faz imprescindível ao pensarmos em elaborar uma proposta didática utilizando a rede social twitter. Alguns pesquisadores já vêm utilizando-a como ferramenta didática e os resultados apontam para 0 aprimoramento das capacidades linguageiras dos alunos, a ampliação de práticas de letramento (GREENHOW, GLEASON, 2012), o aumento do engajamento nas atividades, tempo de execução mais maleável para as tarefas, participação e aprendizagem colaborativa, interações qualitativas, entre outros (CASTRO, 2015). Para a didatização desse gênero, no entanto, não é necessário apenas levar em conta os seus benefícios como também apontar os conflitos, as questões sócio-históricas e as forças sociais que atuam por meio dela, para possibilitar ao aluno a capacidade de agir criticamente no mundo (MARCUSCHI, 2001).

\section{Gênero tweet e ciberculturaremix: proposição didática para o ensino médio}

A nossa proposição didática é baseada na Pedagogia dos Multiletramentos (ROJO, 2012), utilizando princípios da Sequência Didática (DOLZ, NOVERRAZ, SCHNEUWLY, 2004), nos pressupostos da escrita colaborativa (LOWRY, CURTIS, LOWRY, 2004) e na ciber-cultura-remix (LEMOS, 2015), uma vez que temos por objetivo trabalhar com letramento crítico, letramentos multissemióticos, cultura digital e dar subsídios para o professor utilizar a língua estrangeira como instrumento do agir social. No final da proposta, pensando em um percurso espiralado, almejamos que os alunos produzam tweets engajados e reflexivos a partir das leituras críticas que farão durante o processo. Essa é uma proposta e possui um caráter empírico, já que não foi aplicada em sala de aula. 
Quadro 2: Atividades e Percursos Metodológicos

\begin{tabular}{|c|c|}
\hline $\begin{array}{l}\text { Pedagogia dos } \\
\text { Multiletramentos }\end{array}$ & Atividades \\
\hline Prática Situada & 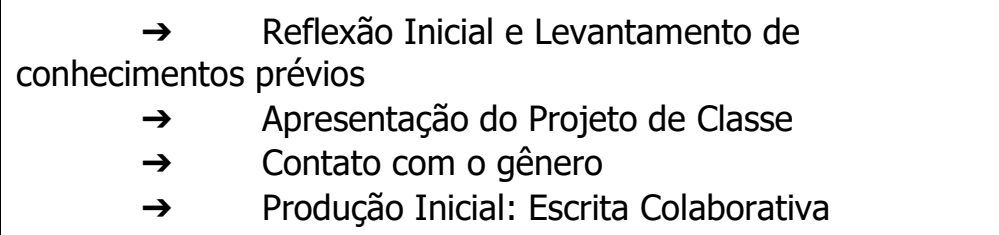 \\
\hline Instrução Aberta & $\begin{array}{cl}\underset{\text { produção }}{\rightarrow} & \text { Avaliação crítica e reescrita da primeira } \\
\underset{\text { Linguagem }}{\rightarrow} & \text { Módulos baseados nas Capacidades de } \\
\rightarrow & \text { Produções Intermediárias: Escrita Colaborativa }\end{array}$ \\
\hline Posicionamento Crítico & 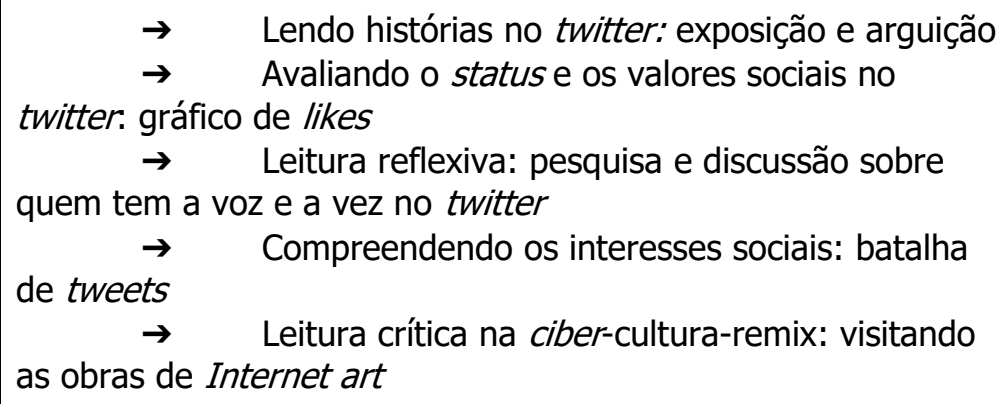 \\
\hline Prática Transformadora & $\begin{array}{l}\rightarrow \text { Evento criativo: 'Histórias cotidianas de luta e } \\
\text { crítica social'. } \\
\rightarrow \quad \text { Produção de tweets, fotos, vídeos e obras de } \\
\text { Internet Artpara exposição à comunidade }\end{array}$ \\
\hline
\end{tabular}

Fonte: Elaborado pelas autoras.

O primeiro momento da nossa proposta é a Prática Situada em que os alunos precisam fazer uma ponte do conhecimento que possuem com novos saberes, na qual visamos uma breve exploração do gênero e introdução do aluno ao projeto de classe, como no início de uma Sequência Didática. Sem termos uma turma específica em mente, torna-se um pouco vago levantarmos conhecimentos prévios, portanto apresentaremos algumas sugestões de como encaminhar essa atividade. Aconselhamos, então, para Atividade 1, a divisão dos alunos em pequenos grupos para que socializem suas próprias experiências quanto aos usos que fazem de redes sociais. 
Quadro 3: Atividade 1 - Reflexão Inicial e Levantamento de Conhecimentos Prévios: Roteiro de Perguntas

1. Você utiliza redes sociais? Quais?

2. O que você faz principalmente nas redes sociais? Alguma pessoa que você conhece faz algum uso diferente de você?

3. Qual você imagina que deve ser o principal objetivo ao usar uma rede social?

4. O que você considera bom e ruim ao utilizar uma rede social?

Fonte: Elaborado pelas autoras.

Depois da Atividade 1, é interessante que seja aberta uma discussão no grande grupo sobre as respostas dos pequenos grupos. O projeto de classe, ou seja, o objetivo final da proposta, poderia ser apresentado para que os alunos fiquem cientes dos objetivos das atividades que irão produzir. Na apresentação do projeto de classe, o professor deve deixar bem explícito o objetivo da proposta, que é produzir tweets que versem sobre o cotidiano dos alunos em língua estrangeira e que eles interajam com outros tweets em língua estrangeira. Escolhemos o tema "cotidiano" para deixar a proposta mais flexível, já que é bem abrangente.

Pensando na realidade de muitos professores, que atuam em contextos adversos e com pouco acesso à internet como o nosso, faremos algumas sugestões para adaptações das atividades. Na Atividade 2 da Prática Situada, a primeira opção seria apresentar a plataforma twitter e permitir a navegação dos alunos por ela de forma dirigida. Essa experiência online é rica, pois apresenta a possibilidade de interação real com o gênero. Os alunos tirariam prints ou fotos com celular dos tweets que chamaram a atenção. A segunda seria que o professor poderia trazer alguns prints de tweets e da plataforma e projetá-los ou trazê-los impressos e também pedir para os alunos contribuir com prints impressos ou no celular. 
Figura 1: Exemplo de print retirado do twitter

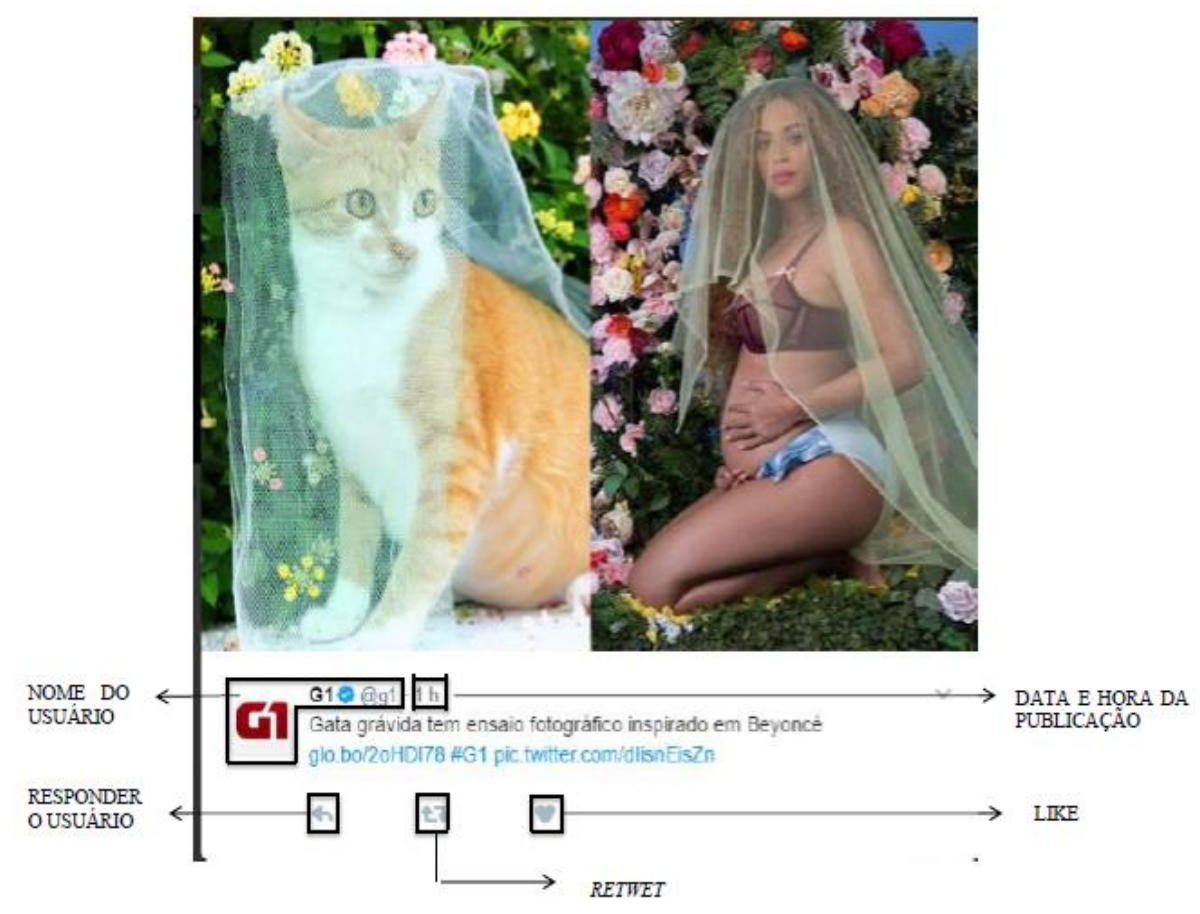

Fonte: Retirado da página do G1 do Twiiter $^{3}$ e editado pelas autoras.

Com os prints em mãos e com o auxílio do professor, os alunos levantariam os possíveis usos do twitter a partir do que foi coletado (lembrando que o professor deve levar alguns prints, caso alguns usos sejam mais priorizados do que outros pelos alunos). Uma possibilidade é a criação de um mapa conceitual com o material reunido e o seu consequente agrupamento. Existem sites que são ferramentas para produzi-lo (o que já poderia ocasionar em uma publicação do resultado no twitter), mas nada impede de ser feito um painel na sala de aula. Para uma condução da proposta com constantes interações no twitter, propomos a criação de uma hashtag para a turma e que seja utilizada em todas as postagens para que se dê uma unidade ao projeto e para que o professor possa acompanhar as produções. A partir da criação do mapa, o professor pode promover algumas reflexões iniciais sobre os aspectos do tweet: sua organização composicional (o nome do usuário, o símbolo de like, de retuíte, a data e a hora de publicação).

\footnotetext{
3Disponível do site: <https://twitter.com/g1>. Acesso em: 31 de mar. 2017.
} 
Sugerimos a Atividade 3, que poderá contribuir para o desenvolvimento dos alunos como produtores-designers criativos de textos multissemióticos na web. Então, sugerimos que os próprios alunos, organizados em pequenos grupos, criem seu perfil online (utilizando a criatividade e aprimorando seu letramento digital e hipertextual para acrescentar imagens, cores, sons, vídeos e demais recursos possíveis). Ou que elaborem um projeto ou esboço do perfil no papel, escolhendo todos os recursos possíveis. Nesse caso, seria interessante que o professor criasse o perfil online, a partir do projeto elaborado, para aqueles alunos que não conseguem o acesso à internet.

Quadro 4: Atividade 3 - Mergulhando no twitter - sugestão de roteiro para elaboração do perfil

1. Determinar a estrutura geral do perfil, criando a timeline do seu grupo;

2. Escolher pessoas e assuntos interessantes para seguir;

3. Interagir com os tweets deles na sua timeline;

4. Seguir também os seus colegas de classe;

5. Postar o primeiro tweet produzido por seu grupo;

6. Interagir com os tweets de seus colegas.

Fonte: Elaborado pelas autoras.

Pensando na estrutura da Sequência Didática, a qual utilizamos também como norte, gostaríamos de introduzir nesse momento a Primeira Produção (Atividade 4). Acreditamos que a ideia de uma produção contínua, espiralada e modular promove o melhor desenvolvimento do indivíduo como autor. Com os pressupostos de escrita colaborativa, cremos que pequenos grupos, como duplas ou trios, são ideais para a criação desse primeiro tweet pelos alunos. Como eles são do Ensino Médio, é cabível que eles já produzam o primeiro tweet em língua estrangeira, mas isso também pode ser adaptado de acordo com as capacidades linguístico-discursivas dos aprendizes.

É vital que o professor conduza os processos de escrita em grupo, estabelecendo: a) as atividades de escrita colaborativa - planejamento, elaboração de texto e revisão; b) os papéis dos participantes - escritor, consultor, revisão, líder do grupo e facilitador; c) estratégias de escrita 
colaborativa - que, nesse caso, acreditamos ser possível, a escrita com um único autor no grupo ou a escrita reativa4; d) os modos de escrita colaborativa sincrônica ou não, no mesmo espaço e tempo ou não; e e) as formas de controle - centralizado, revezado, independente e compartilhado 5 (LOWRY, CURTIS, LOWRY, 2004). O professor deve reforçar a premência da colaboração e que os papeis dos participantes são flexíveis e mutáveis, bem como as atividades de escrita colaborativa (SEVILLA-PAVÓN, 2015; FUNG, 2010) e as formas de controle.

Para o monitoramento e a avaliação da escrita colaborativa, é necessário que o professor crie um mecanismo de acompanhamento dessas interações: se acontecer via chat (que pode ser o DirectMessage, Whatsapp, Messenger etc.), o professor pode pedir para participar dos grupos ou receber prints diários das mensagens; se acontecerem em sala de aula ou em encontros fora delas, 0 professor pode pedir para que cada aluno crie um diário individual de interações em que registre qual foi a sua contribuição e a dos colegas. A partir da produção inicial (e o diário ou o chat pode ser também ferramentas de diagnóstico), o professor identificará as principais dificuldades da turma em relação ao gênero a serem trabalhadas.

Na Instrução Aberta, os alunos poderão ser conduzidos a avaliar criticamente sua primeira produção, buscando compartilhar e negociar os momentos de revisão crítica com todos os participantes. Nesta etapa, trabalhamos apenas com exemplos de atividades que poderão servir para sanar possíveis dificuldades, bem como para melhor sistematizar o estudo do gênero tweet. Pensando na estrutura da Sequência Didática, reunimos aqui alguns

\footnotetext{
${ }^{4}$ Quando há um processo de escrita reativa, os autores escrevem simultaneamente, alterando as produções uns dos outros (LOWRY, CURTIS, LOWRY, 2004).

${ }^{5} \mathrm{As}$ formas de controle dizem respeito ao modo como o controle do desenvolvimento do grupo é gerenciado. O controle centralizado é quando há apenas uma pessoa responsável pelo controle do documento, como um editor ou facilitador. O controle revezado implica quando há um controle centralizado, mas ele é exercido por uma pessoa por turno. O controle independente é quando cada um trabalha separadamente em sua parte e é responsável apenas por ela. O controle compartilhado ocorre quando o poder de decisão e controle é democrático e todos possuem voz e a possibilidade de intervenção no texto de forma mais igualitária (LOWRY, CURTIS, LOWRY, 2004).
} 
temas de atividades, organizados em módulos, que poderão ajudar no estudo sistematizado do gênero de acordo com as capacidades de linguagem (DOLZ, SCHENEUWLY, 2004) que precisam ser aprofundadas pelos alunos.

Quadro 5: Módulos organizados de acordo com as Capacidades de Linguagem

\begin{tabular}{|c|c|c|c|}
\hline Capacidades de Ação & $\begin{array}{l}\text { Capacidades } \\
\text { Discursivas }\end{array}$ & $\begin{array}{c}\text { Capacidades } \\
\text { Linguístico-Discursivas }\end{array}$ & $\begin{array}{l}\text { Capacidades de } \\
\text { Significação }\end{array}$ \\
\hline $\begin{array}{l}\text { Investigação no perfil } \\
\text { de alguns usuários } \\
\text { sobre a relação } \\
\text { temática dos tweets e } \\
\text { a posição social do } \\
\text { autor e a possível } \\
\text { posição do receptor. }\end{array}$ & $\begin{array}{c}\text { Estudo da sequência } \\
\text { descritiva em língua } \\
\text { estrangeira como } \\
\text { forma de apresentar } \\
\text { seu ponto de vista a } \\
\text { outros. }\end{array}$ & $\begin{array}{l}\text { Compreensão da } \\
\text { apropriação da } \\
\text { oralidade na cultura } \\
\text { escrita das redes } \\
\text { socais: ausência de } \\
\text { pontuação, } \\
\text { abreviações, } \\
\text { onomatopeias, } \\
\text { neologismos, etc. }\end{array}$ & $\begin{array}{c}\text { Análise do } \\
\text { objetivo social do } \\
\text { gênero em } \\
\text { relação a quem o } \\
\text { produz e seu } \\
\text { conteúdo } \\
\text { temático, visando } \\
\text { seu status como } \\
\text { TrendingTopics. }\end{array}$ \\
\hline $\begin{array}{l}\text { Inferências sobre o } \\
\text { conteúdo temático de } \\
\text { alguns tweets e } \\
\text { acontecimentos } \\
\text { contemporâneos. }\end{array}$ & $\begin{array}{c}\text { Exame do layout do } \\
\text { gênero tweet e o papel } \\
\text { desse na } \\
\text { plurivocalidade do } \\
\text { gênero. }\end{array}$ & $\begin{array}{l}\text { Elementos de coesão } \\
\text { textual em tweets: } \\
\text { elaborando sínteses. }\end{array}$ & $\begin{array}{c}\text { Levantamento } \\
\text { léxico-semântico } \\
\text { das palavras e } \\
\text { temas mais } \\
\text { recorrentes e } \\
\text { análise } \\
\text { sociodiscursiva. }\end{array}$ \\
\hline
\end{tabular}

Fonte: Elaborado pelas autoras.

A partir de cada módulo, pode ser realizada uma produção colaborativa intermediária com o propósito de promover o desenvolvimento autoral dos alunos em alguns desses aspectos, para que a produção final reflita o processo da aprendizagem. Essa é uma nova oportunidade para que eles solucionem suas dificuldades percebidas na produção inicial. Sugerimos que sejam revistos e redefinidos os critérios de escrita colaborativa, por exemplo, invertendo os papéis dos participantes. Após a escrita, a Atividade 5 será a revisão crítica e a reescrita dos tweets, eles poderão ser postados na timeline dos participantes. Assim, todos poderão interagir com likes, retweets, comentários, respostas ou abstenção de reação. Além disso, estas produções poderão ser incrementadas com a publicação de fotos ou vídeos criativos que dialoguem ou reforcem 0 conteúdo do tweet. 
Para isso, cada grupo produzirá sua foto ou vídeo ou pesquisará fotos ou vídeos que deseje utilizar. Para aqueles que não conseguem acessar a internet, poderão ser coletadas imagens ou vídeos e novamente ser elaborado um projeto de publicação no twitter, que será postado na web pelo professor. Outra opção, nestes casos de falta de acesso, é que os alunos que têm condições dividam seu computador e internet (de casa) com os demais para a realização das atividades; isso dependerá da realidade da turma. Para a produção e edição dos vídeos, é importante que os alunos atentem-se às particularidades do twitter, que por ser um microblog aceita vídeos menores.

$\mathrm{Na}$ etapa de Posicionamento Crítico, é preciso promover a conscientização crítica dos alunos quanto a uma relação mais complexa e aprofundada do gênero abordado. A partir disso, nossa sugestão de posicionamento crítico é sobre a cultura da visibilidade nas redes sociais e sobre o capital cultural forjado, provendo aos alunos o questionamento se de fato a internet democratiza mais as vozes em nossa sociedade, se os silenciados de nossa cultura ocupam um espaço nesse meio (MARCUSCHI, 2001) e que espaço é esse.

A Atividade 6 seria pedir para que os alunos revisitassem o twitter em busca de formas como as pessoas falam sobre si, seu cotidiano e suas histórias. Cada aluno da turma deve escolher um usuário do twitter e selecionar os seus principais tweets. Como consequência disso, os alunos poderão montar um vídeo com as imagens escolhidas com a ajuda de um editor de vídeos, inclusive um editor de dispositivos móveis, o qual pode ser mais acessível e mais conhecido por eles. Ou, por outro caminho, o professor reúne todas as imagens e edita um único vídeo. Outra opção é utilizar impressão e criar uma micro exposição de forma criativa, teias, varais etc. e os alunos escolhem, na hora, os usuários com os quais mais se identificam para elaborar sua arguição que será voltada para os colegas de classe. Durante a exposição, cada aluno deve relatar: 
Quadro 6: Atividade 6 - Exposição e arguição: histórias do twitter

1 - O perfil geral do usuário escolhido.

2 - A justificativa da escolha.

3 - Os critérios da seleção dos tweets (se forem os alunos que os tiverem escolhido).

4 - A descrição das imagens.

5 - Como essas imagens descrevem essa pessoa.

6 - O que é valorizado por ela.

7 - As interações e reações de outras pessoas em relação a ela.

8 - O status dessa pessoa para a rede social twitter e seus usuários.

9 - Uma relação entre o status do perfil desse usuário e o que ela posta.

Fonte: Elaborado pelas autoras.

É provável que os alunos escolham usuários que têm mais visibilidade social ou valor para eles, cantores, atores, jogadores de futebol, youtubers, entre outros. No final da atividade, faz-se uma discussão geral em que os alunos podem observar as estratégias mais recorrentes que os indivíduos utilizam para contar sua história, criando uma espécie de gráfico de likes, assim que a gradação é construída. Por exemplo, os itens analisados podem ser a própria imagem, o photoshop, objetos de marca, atividades profissionais. Conforme eles vão aparecendo, o professor vai registrando e para cada recorrência ganha um like (símbolo do coração) para que possam realizar um comparativo sobre o que é mais valorizado pelos usuários do twitter escolhidos por eles. $O$ professor pode conduzir a discussão, questionando se o que é mais valorizado pelos usuários equivale às preferências deles, se a imagem criada pelos usuários reflete realidade, as relações entre realidade e a virtualidade e quais as implicações de se valorizar os itens mais pontuados os quais podem ser beleza, riqueza, amigos, festas, ter um corpo perfeito etc.

Achamos essencial apresentar um contraponto aos tweets analisados anteriormente, cujos objetivos são promover a si mesmo. Lançamos aos alunos, então, o seguinte desafio para a Atividade 7: encontrar usuários e perfis do twitter que tenham muita popularidade e que mostrem pessoas com fotos como elas são e não a melhor produção delas; pessoas que não estão no padrão de beleza; que não cultuam a própria imagem; pessoas que postam sobre minorias; direitos humanos; que se preocupam com os problemas locais, 
nacionais, globais; e que não são de sua maioria de países ocidentais. Compilamos aqui alguns perfis que podem ajudar nas buscas:

Quadro 7: Subsídios para o professor: visita aos perfis de usuários

\begin{tabular}{|l|l|}
\hline \multicolumn{1}{|c|}{ Pefil de usuário } & \multicolumn{1}{c|}{ Principais Temas } \\
\hline $\begin{array}{l}\text { InvisibleChildren } \\
\text { @invisible (língua inglesa) }\end{array}$ & $\begin{array}{l}\text { Luta contra violência e exploração em } \\
\text { comunidades mais afastadas e vulneráveis }\end{array}$ \\
\hline $\begin{array}{l}\text { Amnesty West Africa } \\
\text { @AmnestyWARO (língua inglesa) }\end{array}$ & $\begin{array}{l}\text { Defesa dos direitos humanos no leste e } \\
\text { centro da África. }\end{array}$ \\
\hline $\begin{array}{l}\text { Mining Injustice } \\
\text { @mininginjustice (língua inglesa) }\end{array}$ & $\begin{array}{l}\text { Solidariedade às comunidades minoritárias } \\
\text { ao redor do mundo. }\end{array}$ \\
\hline $\begin{array}{l}\text { Hyperallegirc } \\
\text { @hyperallergic (língua inglesa) }\end{array}$ & $\begin{array}{l}\text { Revista de arte contemporânea e } \\
\text { resistência }\end{array}$ \\
\hline $\begin{array}{l}\text { Quebrando o Tabu } \\
\text { @QuebrandooTabu (língua portuguesa) }\end{array}$ & $\begin{array}{l}\text { Leituras críticas sobre notícias, fatos } \\
\text { históricos e discussões atuais. }\end{array}$ \\
\hline $\begin{array}{l}\text { Young ArtKommunity } \\
\text { @FirstSiteYAK (língua inglesa) }\end{array}$ & $\begin{array}{l}\text { Jovens que programam eventos e } \\
\text { atividades artísticas. }\end{array}$ \\
\hline $\begin{array}{l}\text { Mafalda Quotes } \\
\text { @MafaldaQuotes (língua espanhola) }\end{array}$ & $\begin{array}{l}\text { Quadrinhos da personagem de Joaquín } \\
\text { Salvador Lavado (Quino) - críticas sociais. }\end{array}$ \\
\hline $\begin{array}{l}\text { Cultura Colectiva } \\
\text { @CulturaColectiva (língua espanhola) }\end{array}$ & $\begin{array}{l}\text { Meio de difusão de atividades artísticas, } \\
\text { culturais e sociais. }\end{array}$ \\
\hline
\end{tabular}

Fonte: Elaborado pelas autoras.

Os perfis acima são de usuários que promovem reflexões ou alguma forma de luta social, utilizam formas diferenciadas para contar as histórias como os perfis ligados à arte, que talvez sejam úteis para inspirá-los para a produção final. Para discussões sobre o outro lado da cultura do broadcast yourselff, indicamos os vídeos "Are youlost in the world like me?", de Steve Cuts e \#LIKELIFE World withvs World Without Social Media, da HayotFilms, que podem ser encontrados no Youtube - essas sugestões podem se tornar rapidamente obsoletas pela velocidade de transformação do conteúdo online.

${ }^{6}$ Em uma tradução literal: "transmita-se", ou seja, promova-se e mostre-se por meio da internet. Fenômeno muito comum nas redes sociais. 
Para o fechamento desse momento de reflexão da Ativdade 7, sugerimos uma batalha de tweets que já acontece nas redes sociais com fotos de dois usuários ou pessoas famosas e a pergunta: "quem ganha?". Os alunos podem escolher dois tweets que se contraponham: pessoas famosas produzidas e pessoas comuns, tweets sobre assuntos frívolos e sobre assuntos de relevância social, entre outros e postá-los no twitter ou pedir para que colegas da escola e da comunidade votem e no fim relatar aos colegas o que tem mais peso social.

A última atividade do posicionamento crítico será um pontapé para a etapa de práticas transformadoras. Em um dos artigos do website da revista Hyperallergirc', são apresentadas algumas obras premiadas de Internet Art que fazem algumas leituras que saem do senso comum sobre o cotidiano fazendo remixagens com diferentes textos. Nesse link, existem vários hipertextos que podem levar os alunos a conhecerem mais profundamente o trabalho dos autores. Os alunos podem escolher uma obra que tenha chamado atenção e criar um tweet sobre ela no twitter ou em uma simulação da rede social twitter em um painel na classe, fazendo a seguinte ficha técnica em língua estrangeira:

Quadro 8: Atividade 4 - Arte na Ciber-cultura remix

Nome da obra:

Nome do autor:

Dialoga com quais temas:

Materiais utilizados-Processos de criação:

Apreciação crítica:

Fonte: Elaborado pelas autoras.

$\mathrm{Na}$ etapa de Práticas transformadoras, pensamos em desenvolver colaborativamente, por meio de diálogos e negociações com os alunos, um evento criativo sobre o tema: Histórias cotidianas de luta e crítica social. Esse evento, poderá se configurar como uma mini-mostra de Arte Eletrônica aberta a toda a comunidade, divulgada e comentada pelos alunos nas timelines do

7 Disponível no site: <http://hyperallergic.com/263538/best-of-2015-our-top-10-works-ofinternet-art/>. Acesso em: 22 jan. 2017. 
Twitter, nas quais serão compartilhadas as obras produzidas pelos próprios alunos.

Sugerimos que esse evento seja organizado em duas frentes: 1. Exposição online de criações dos próprios alunos na timelinedos grupos, por meio da publicação de tweets, fotos, vídeos e obras de Internet Art (a exemplo daquelas já trabalhadas através do website da revista Hyperallergirc), que componham "Histórias cotidianas de luta e crítica social";2. Através de uma exposição desses mesmos tweets, fotos, vídeos e obras de Internet Art no ambiente físico da escola, em uma data especial em que toda a comunidade prestigie a produção dos alunos. Nesse caso, as produções poderão ser expostas impressas (no caso das fotos e tweets), ou em um projetor digital, sendo mais coerente para as realidades escolares que não possuem acesso à internet. Sugerimos que os convites e a divulgação do evento sejam realizados pelos alunos, através de mídias digitais e eletrônicas, como o próprio twitter, o facebook, a rádio local do município e os possíveis jornais online também do município.

Para as produções, sugerimos que os alunos sejam incentivados a coletar histórias de lutas e críticas sociais em seu contexto mais próximo, através de entrevistas e conversas com os próprios familiares, amigos, vizinhos, pessoas do bairro, ou por meio de visitas a entidades sociais como lares para idosos, abrigos de menores, clínicas de dependência química, escolas, movimentos sociais e demais realidades que os próprios alunos percebam que possam ser exploradas criticamente É interessante que os alunos sintam a necessidade de realizar ações concretas que contribuam com a história de luta e crítica social daquelas pessoas, oportunizando o desenvolvimento do ser humano enquanto ser solidário, ético, crítico e responsável. As histórias coletadas serão retextualizadas na produção de tweets, imagens, vídeos e demais obras de Internet Art a serem pensadas pelos alunos.

Para a produção escrita dos tweets, os alunos novamente colocarão em prática a escrita colaborativa, sendo que já poderão conduzir os passos do trabalho em grupo de forma mais autônoma, mas sem dispensar o 
acompanhamento do professor enquanto mediador de todo o processo. Para a produção dos vídeos, eles novamente observarão os critérios de composição para publicação no twitter que, como vimos, são mais específicos. $\mathrm{E}$, para a produção da arte eletrônica, há diversos programas gráficos disponíveis na web, que possibilitam a criação de imagens, vídeos, sons, logotipos e ilustrações ${ }^{8}$. Há também programas que funcionam online, sem necessidade de baixar no computador, como, por exemplo, o YouiDrawe o Escape Motions ${ }^{9}$. Esses programas são gratuitos e servem para criar arte digital, desenhando, pintando e produzindo logotipos.

Imaginamos que ao serem apreciadas por toda a comunidade escolar, as produções dos alunos ganharão sentidos mais completos tanto para quem aprecia, quanto para quem produz. Além disso, essa apreciação pública possibilitará levar a todos a experiência de recontar histórias de lutas e críticas sociais tão próximas de cada um, por meio de instrumentos digitais.

\section{Considerações finais}

Esperamos que esta proposta didática, ao ser aplicada com as devidas adaptações às diversas realidades escolares, possa contribuir consideravelmente não só para a aprendizagem de língua estrangeira, mas sobretudo para a formação autoral, crítica, reflexiva e colaboradora de cada um dos alunos e professores envolvidos. Como professoras da rede pública de ensino, conhecemos as adversidades que enfrentamos dia a dia, notadamente quando pensamos em desenvolver práticas de ensino realmente críticas e transformadoras. Considerando que estamos inseridos em uma época

\footnotetext{
${ }^{8}$ Alguns programas gráficos são: Gimp, Blender, Paint, LMMS, Audacity. Disponíveis nos respectivos sites: <https://www.gimp.org/downloads/>; $<$ http://www.baixaki.com.br/download/blender.htm $>$; $<$ h ttp://www.baixaki.com.br/download/paint-net.htm>; <https://lmms.io/download/\#windows>; <https://audacity.softonic.com.br>. Acesso em: 20 abr. 2017.
}

9 Disponíveis nos respesctivos sites: <https://www.youidraw.com/\#site>; $<$ http://safepctuga.blogspot.com.br/2010/05/criar-arte-digital-online.html>. Acesso em: 27 jan. 2017. 
globalizada, em uma sociedade que vive a cibercultura de todas as formas possíveis e cada vez mais veloz, entendemos com uma grande disparidade termos pouco apoio necessário no ambiente escolar para a realização de atividades didáticas que envolvam as TDIC.

Por isso, entendemos que desenvolver e aplicar uma proposta didática que envolva os multiletramentos em sala de aula da rede pública é um grande desafio. É por esse motivo que gostaríamos de dividir a autoria dessa proposta didática com cada professor que venha a ser aplicador. Fazemos isso pensando na importância de criar colaborativamente, adaptando esta proposição que ainda é muito ampla, mas que foi pensada justamente para servir como inspiração para um trabalho efetivo de ensino-aprendizagem e transformação social. Como afirma Rojo (2013, p. 7), é necessário que "a instituição escolar prepare a população para um funcionamento da sociedade cada vez mais digital e também para buscar no ciberespaço um lugar para se encontrar, de maneira crítica, com diferenças e identidades múltiplas".

Embora os desafios sejam muitos, ainda acreditamos que seja possível preparar nossos alunos para serem produtores, designers, criadores significativos em plena ciber-cultura-remix.

\section{Referências}

AGUIAR, Maria Juliana Dias; FISCHER, Adriana. A pedagogia dos multiletramentos: Uma proposta para formação continuada de professores. Leia Escola, Campina Grande, v. 12, n. 2, p.106-130, jan. 2012.

ALLEN, Nancy]. et al. What experienced collaborators say about collaborative writing. Journal of Business and Technical Communication, vol. 1, n. 2, p. 7090, 1997.Disponível em:

$<$ http://rel.sagepub.com/content/41/1/18.full.pdf+html>. Acesso em: 07 jan. 2017.

BAKHTIN, Michael. Estética da Criação Verbal. 4. ed. São Paulo: Martins Fontes, 2003. 
BRANCO, Sérgio; BRITO, Walter. O que é CreativeCommons?: Novos modelos de direito autoral em um mundo mais criativo. Rio de Janeiro: Fgv, 2013. 176 p. Disponível em:

<http://bibliotecadigital.fgv.br/dspace/bitstream/handle/10438/11461/O que é Creative Commons.pdf >. Acesso em: 23 abr. 2017

BUSH, Jonathan.; ZUIDEMA, Leah. Professional Writing in the English Classroom: Professional Collaborative Writing: Teaching, Writing, and Learning -- Together. English Journal, vol. 102, n. 4, p. 107-110, 2013.

CASTRO, Vania Carvalho. Turn on your mobile devices in the english classes [manuscrito]: Tweets no processo de escrita colaborativa on-line do gênero personal recount. 2015. 213 f. Dissertação (mestrado) - Universidade Federal de Minas Gerais, Faculdade de Letras, 2015.

COSCARELLI, Carla. Hipertextos na teoria e na prática. Belo Horizonte: Autêntica, 2012.

FUNG, Yong Mei. Collaborative Writing Features. RELC Journal, vol. 41, n. 1, vol. 18-30, 2010.Disponívelem: <sagepub.co.uk/journals>. Acesso em: 07-012017.

GREENHOW, Christine.; GLEASON, Benjamin. Twitteracy: Tweeting as a new Literacy Practice. The Educational Forum, vol. 76, p. 464-478, 2012.

GRUPO DE NOVA LONDRES. Pedagogy of Multiliteracies: Designing Social Futures. In COPE, Bill.; KALANTZIS, Mary. (Ed.).Multiliteracies: literacy learning and the design of socialfutures. Routledge: Psychology Press, 2000, p.9-37.

JEWITT, Carey. Multimodality and literacy in school classrooms. Review of Research in Education, v. 32, n. 1, p. 241-267, 2008.

LEMOS, André. Cibercultura. Alguns Pontos para compreender a nossa época. In: Lemos, André.; Cunha, Paulo. (Orgs.). Olhares sobre a Cibercultura, Sulina, Porto Alegre, 2003; pp. 11-23.

. Cibercultura e Mobilidade: A Era da Conexão. In: CONGRESSO

BRASILEIRO DE CIÊNCIAS DA COMUNICAÇÃO, 2005, Rio de Janeiro. Anais...

Rio de Janeiro: Intercom - Sociedade Brasileira de Estudos Interdisciplinares da Comunicação, 2005. Disponível em:

<file:///C:/Users/vo/Downloads/Cibercultura e Mobilidade _ A Era da conexão André Lemos.pdf>. Acesso em: 21 jan. 2017.

. Ciber-cultura-remix. In: SEMINÁRIO SENTIDOS E PROCESSOS, apresentação a mesa "Redes: criação e reconfiguração", 2015, São Paulo. Anais... São Paulo: Itaú Cultural, agosto de 2015. Disponível em: 
<http://www.facom.ufba.br/ciberpesquisa/andrelemos/remix.pdf>. Acesso em: 21 jan. 2017.

LOWRY, Paul Benjamin; CURTIS, Aaron; LOWRY, Michelle Renèe. Building a taxonomy and nomenclature of collaborative writing to improve interdisciplinary research and practice. Journal of Business Communication, vol. 41, n. 1, p.6699, 2004. Disponível em: <http://job.sagepub.com/cgi/ reprint/41/1/66>. Acesso em: 07 jan. 2017.

MARCHIORI, Patrícia Zeni.; GRIEF, Ana Carolina. Atividade de escrita colaborativa: percepção de alunos, princípio cooperativo de Grice e social loafing. Educ. Pesqui, São Paulo, v. 40, n.2, p. 467-482, abr./ jun., 2014.

MARCUSCHI, Luiz. Antônio. A questão do suporte dos gêneros textuais. $D L C V$, n. 1, João Pessoa, p. 9-40, out. 2003,

. O hipertexto como um novo espaço de escrita em sala de aula.

Linguagem \& Ensino, v. 4, n. 1, p. 79-111, 2001.

NERY, Tiago. Ciber-cultura-remix: a experiência do Carrinho Multimídia na ciber cidade de Salvador - Bahia. In: CONGRESSO BRASILEIRO DE CIÊNCIAS DA COMUNICAÇÃO, 2015, Rio de Janeiro. Anais... Rio de Janeiro: Intercom Sociedade Brasileira de Estudos Interdisciplinares da Comunicação, 2015. Disponível em: <http://portalintercom.org.br/anais/nacional 2015/resumos/R10-1117-1.pdf >. Acesso em: 21 jan. 2017.

PREDIGER, Angélica; KERSCH, Dorotea. Usos e desafios da multimodalidade no ensino de línguas. Signo, Santa Cruz do Sul, v. 38, n. 64, p.209-227, jan. 2013.

PINHEIRO. Petrilson Alan. A escrita colaborativa por meio do uso de ferramentas digitais: ressignificando a produção textual no contexto escolar. Calidoscópio, São Leopoldo, v. 9, n. 3, p.226-239, 2011.

PINHEIRO, Regina Claudia. Letramentos demandados em cursos on-line: por uma redefinição do conceito de letramentos hipertextuais. Tese - Programa de Pós-Graduação em Linguística. Universidade Federal do Ceará, 2013. Disponível em:

<https://www.dropbox.com/sh/hg28nkzgbleuem1/AADJEJDGFq6WQYOwM7Mav XdYa?dl=>. Acesso em: 21 jan. 2017.

ROJO, Roxane. (Org.). Escola conectada: Os multiletramentos e as TDIC. São Paulo: Parábola, 2013.

SANTANA, Camila Lima. Visibilidade mediada [recurso eletrônico]: estratégias e ações docentes no twitter. 2014. 257 F. Tese (Doutorado). Universidade

Federal da Bahia. Faculdade de Educação, Salvador, 2014. 
SCHNEUWLY, Bernnard; DOLZ, Joaquim. Gêneros e progressão em expressão oral e escrita - elementos para reflexão sobre uma Suíça (francófona). In: SCHNEUWLY, B; DOLZ, J. Gêneros orais e escritos na escola. Campinas, São Paulo; Mercado de Letras: 2004.

SCHNEUWLY, Bernard; DOLZ, Joaquim.; NOVERRAZ, Michele. Sequências Didáticas para o oral e a escrita: apresentação de um procedimento. SCHNEUWLY, Bernard; DOLZ, Joaquim. Gêneros orais e escritos na escola. Campinas, São Paulo; Mercado de Letras: 2004, p. 95- 128.

SEVILLA-PAVÓN, Ana. Examining Authorship in Collaborative Writing Tasks through Digital Storytelling. European Journal of Open, Distance and ELearning, v. 18, n. 1, 2015.

SILVA, Glayse Ferreira Perroni. O Twitter como um novo gênero digital para o ensino de língua materna a partir de uma análise textual e discursiva do gênero literário microconto. 2013. 157 f. Dissertação (mestrado) - Universidade de Taubaté, Departamento de Ciências Sociais e Letras, 2013.

SOARES, Magda. Novas práticas de leitura e escrita: letramento na cibercultura. Educação e Sociedade, v. 23, n.81, 2002, p. 143-160.

THE NEW LONDON GROUP. A pedagogy of multiliteracies: Designing social futures. Harvard educational review, 66(1), 1996, 60-93.

VIEIRA, Josenia; SILVESTRE, Carminda. Introdução à multimodalidade: Contribuições da Gramática Sistêmico-Funcional Análise de Discurso Crítica Semiótica Social. Brasília: Antunes Vieira, 2015. 170 p.

VYGOTSKY, Lev Semenovich. Pensamento e linguagem. 2. ed. Tradução de Jefferson Luiz Camargo. São Paulo: Martins Fontes, 1998. p. 65-101. (Psicologia e Pedagogia).

XAVIER, Antônio Carlos. Leitura, texto e hipertexto. In: Marcuschi, L. A; Xavier A. C (Orgs). Hipertextos e gêneros digitais: novas formas de construção do sentido. $2^{a}$ ed. Rio de Janeiro: Lucerna, 2007, p. 170-180.

ZAGO, Gabriela. Usos sociais do Twitter: proposta de tipologia a partir do capital social. 2008. Disponível em:

<http://www.pontomidia.com.br/raquel/teorica.htm>. Acesso em: 30 jan. 2017. 